\title{
Early Detection of Breast Cancer is an Important Byproduct of Computed Tomography of the Chest
}

Johannes Gossner (D)

Evangelisches Krankenhaus Göttingen-Weende, Diagnostic and Interventional Radiology, Göttingen, Germany

Cite this article as: Gossner J. Early Detection of Breast Cancer is an Important Byproduct of Computed Tomography of the Chest. Eur J Breast Health 2020; 16(4): 298-299.

\section{Dear Editor,}

Early detection reduces breast cancer related mortality and morbidity (1). But screening with mammography has several shortcomings: cancer detection in dense breast tissue is limited and there is the problem of overdiagnosis and overtreatment. It also has to be noticed that a substantial portion of invited women are not participating in organized screening programs. On the other hand, a large number of women are undergoing computed tomography of the chest (CT) for various indications (for example for the work-up of suspected lung cancer, complicated cases of pneumonia or pulmonary embolism) and in these CT scans the breasts are included without being systematically reported.

The detection of breast lesion in unenhanced CT scans (i.e. without the application of contrast media) depends on the density of the breast parenchyma, which is known from mammography. But most CT scans of the chest are performed using iodinated contrast media (for the opacification of the vessels) and as malignant breast tumors show a strong contrast uptake they can be distinguished from the normal breast parenchyma (2). In a study on 149 women, contrast-enhanced chest CT detected even more breast cancers than mammography or sonography (3). In contrast to mass lesions, microcalcifications, which are the hallmark of diagnosis of a ductal carcinoma in situ (DCIS), cannot be detected with conventional chest CT (2).

The number of CT scans is steadily increasing. According to the German National Agency for Radiation protection (Bundesamt für Strahlenschutz) around 1.75 million chest CT examinations have been performed in 2014 (4). In a study by Hansen and Jurik from Denmark around $33 \%$ of chest CT examinations are performed in women between 45 and 80 years and $19 \%$ in women between 45 and 64 years (5). According to this data around 332.500 chest CT examinations in women between 45 and 64 years ("screening age") have been performed in 2014 in Germany. For comparison, 2.86 million women participated in the German breast cancer screening program in 2014 , equating to $54 \%$ of the invited women (6). I.e. $6.3 \%$ of women in the "screening age" undergo chest CT annually with the possibility for early breast cancer detection. There are several retrospective studies reporting about incidental breast findings on chest CT. Reported incidence ranges from $0.6 \%$ to $7.6 \%$ with a mean frequency of $3 \%(7-13)$. Of these incidental findings around $39.9 \%$ are malignant, with a reported between 17.3 and $69 \%$ (7-15). Given the assumption that $6.31 \%$ of women in the "screening age" receive computed tomography of the chest annually, a $3 \%$ chance of detection of an incidental breast finding and a rate of malignancy of 39.9\% around 3980 incidental breast cancers in women between 45 and 64 could be detected annually in Germany with the help of chest CT scans.

In conclusion, the dedicated review of breast parenchyma in women undergoing CT of the chest may detect a substantial number of breast cancers, in fact about $1.2 \%$ of women undergoing chest CT will show an incidental detected breast cancer. Given the clinical importance of an early diagnosis of breast cancer the chance of detecting incidental breast cancers on chest CT should be taken. This is especially important in countries without established breast cancer screening programs. It has to be emphasized that CT should not be used as a primary screening modality of breast cancer, but if performed for other reasons, a systematic review of the breast is mandatory. 


\section{Gossner J. Early Detection of Breast Cancer is an Important Byproduct of Computed Tomography of the Chest}

Peer-review: Externally peer-reviewed.

Conflict of Interest: The author have no conflicts of interest to declare.

Financial Disclosure: The author declared that this study has received no financial support.

\section{References}

1. Schattner E. Correcting a decade of negative news about mammography. Clin Imaging 2020; 60: 265-270. (PMID: 30982701) [Crossref]

2. Gossner J. Intramammary findings on CT of the chest- a review of normal anatomy and possible findings. Pol J Radiol 2016; 81: 415-421. (PMID: 28058068) [Crossref]

3. Inoue M, Sano T, Watai R, Ashikaga R, Ueda K, Watatani Y, Nishimura Y. Dynamic multidetector CT of breast tumors: diagnostic features and comparison with conventional techniques. AJR 2003; 181: 679-686. (PMID: 12933459) [Crossref]

4. Nekolla EA, Schegerer AA, Griebel J, Brix G. Frequency and doses of diagnostic interventional X-ray applications. Trends between 2007 and 2014. Radiologe 2017; 57: 555-562. (PMID: 28361179) [Crossref]

5. Hansen J, Jurik AG. Analysis of current practice of CT examinations. Acta Oncol 2009; 48: 295-301. (PMID: 18923941) [Crossref]

6. Kooperationsgemeinschaft Mammographie. Jahresbericht Qualitätssicherung 2014. Available from: https://fachservice.mammo-programm. de/download/qualitaetsberichte/MAMMO_Quali_Jahresbericht_2014_20161213_web02.pdf, accessed 2.4.2020

7. Hussain A, Gordon-Dixon A, Almasawy H, Sinha P, Desai A. The incidence and outcome of incidental breast lesions detected by computed tomography. Ann R Coll Surg Engl 2010; 92: 124-126. (PMID: 19995489) [Crossref]
8. Lin WC, Hsu HH, Li CS, Yu JC, Hsu GC, Yu CP, Chang TH, Huang GS. Incidentally detected enhancing breast lesions on chest computed tomography. Korean J Radiol 2011; 12: 44-51. (PMID: 21228939) [Crossref]

9. Surov A, Fiedler E, Wienke A, Holzhausen HJ, Spielmann RP, Behrmann C. Intramammary incidental findings on staging computer tomography. Eur J Radiol 2012; 81: 2174-2178. (PMID: 21742452) [Crossref]

10. Monzawa S, Washio T, Yasuoka R, Mitsuo M, Kadotani Y, Hanioka K. Incidental detection of clinically unexpected breast lesion by computed tomography. Acta Radiol 2013; 54: 374-379. (PMID: 23395815) [Crossref]

11. Poyraz N, Emlik GD, Keskin S, Kalkan H. Incidental breast lesions detected on computed tomography. Eur J Breast Health 2015; 11: 163-167. (PMID: 28331715) [Crossref]

12. Healey TT, Agarwal S, Patel S, Ratanaprasatporn L, Ratanaprasatporn L, Lourenco AP. Cancer yield of incidental breast lesions detected on computed tomography. J Comput Assist Tomogr 2018; 42: 453-456. (PMID: 29016373) [Crossref]

13. Krug BG, Houbois C, Grinstein O, Borggrefe J, Puesken M, Hanstein B, Malter W, Maintz D, Hellmich M. Focal breast lesions in clinical CT examinations of the chest: a retrospective analysis. Fortschr Röntgenstr 2017; 189: 977-989. (PMID: 28683503) [Crossref]

14. Ismail AR. Incidental breast lesions detected on diagnostic CT scans: a 3-year prospective study. J Clin Oncol 2011; 29 (Supplement): 69. [Crossref]

15. Moschetta M, Scardapane A, Lorusso V, Rella L, Telegrafo M, Serio G, Angelelli G, Stabile Ianora AA. Role of multidetector computed tomography in evaluating incidentally detected breast lesions. Tumori 2015; 101 : 455- 460. (PMID: 25908028) [Crossref] 